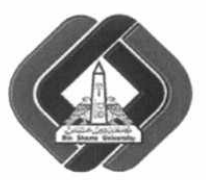

\author{
International Journal of Intelligent Computing \\ and Information Science
}

\title{
FRAMEWORK FOR GAMIFICATION BASED E-LEARNING SYSTEMS FOR HIGHER EDUCATION IN EGYPT
}

\author{
M. R. Elabnody \\ M. M. Fouad \\ F. Maghraby \\ A. Hegazy \\ College of Computing \& Information Technology (CCIT) \\ Arab Academy for Science, Technology, and Maritime Transport (AASTMT) \\ elabnody@msn.com_mohamed_mostafa@aast.edu fahima.maghraby@hotmail.com abdheg@yahoo.com
}

\begin{abstract}
With gamification, design elements known from games can be used in several ways; Businesses have begun to use gamification to enhance profitability, staff have turned work into a game in order to reduce the monotony, serious applications like work and education are being started using mechanisms borrowed from game design, by adding elements from games into non-game e-learning applications. This study aims to identify how the elements of gamification affect user experience and increase their engagement with registered subjects. Through a dynamic question selection approach based on the gamification tactics, the real exams of a number of students showed the improvement of their knowledge acquisition by $55 \%$ over the traditional examination approaches.
\end{abstract}

Keywords: e-learning; games-based learning; gamification; gamified e-learning course; higher education;

\section{Introduction}

Education systems based on four key elements teacher, the student, the university, and the curriculum which teaches. Egypt educational institutions face major problems around student motivation and engagement, inability to take out of student talents and abilities, and the fear of an interview that with cynicism. The spirit of seriousness which granted by the school or university, which reduces the incentive for students to go or learn, and curricula depend on conservation and indoctrination. Also, the student not interesting to take online exams after they failed the first time. Gamification offers an opportunity to help educational institutions to solve these problems. Provide insight into how educational institutions can use gamification, to attract students and thereby increase their learning. Also applying the right gamification element to the right user to increase the motivation and participation, skill teachers who use the system, and identify the behaviors to change in the learners.

Gamification is defined as the use of game design elements in non-game contexts [1]. It's the techniques that designers use in games that can be implemented to solve actual problems in education, by applying game mechanics and game design techniques to engage and motivate people to do a certain behavior [2]. The term has been increasingly popular since 2010 used as a process for creating motivation in users' activities to improve user experience and involvement in non-game services [3]. The gamification provides positive effects on the users using it. There are two main aspects: 1) the role of the context 
being gamified which main the structure and game dynamics should have a relevant relationship with the content [4], and 2) the qualities of the users [5].

In 2014, True Life Game project introduce the concepts of gamification into learning [6]. In 2015, Arizona State University has added five interactivity story-based games to its scientific curriculum. Within each story-based game, students will take a number of leadership roles, and the task of solving complex environmental and sustainability aspects [7].

In recent years gamification has seen rapid adoption in business, marketing, management, and ecology. Loyalty programs such as Foursquare and Nike+ are often given as examples of successful gamified online education sites such as Coursera, code academy and khan academy use game elements to better engage users. The more courses that users complete, the more badges they earn [8]. Mechanics, elements and ideas that can be used in gamification [9], consist of three particular relevance to education are: (1) mechanical elements, such as Onboarding, Tutorials, Progress, Feedback, Time Pressure; (2) personal elements, such as status, visibility, random rewards, time-dependent rewards, leaderboards, and rankings; and (3) emotional elements such as Social Status, Competition, Certificates [10].

The study presents a strategy to use new technologies in conjunction with e-learning platform and gamification, creates interest in the students for the material and generates a significant learning experience by examination whether the concept of gamification can be viable when applied within elearning, what's to be considered when implementing the concept within e-learning, and identify a suitable gamification approach for information system courses.

The rest of the paper is organized as follows: Section 2 discusses the related work, section 3 presents the research methodology, section 4 discusses the system implementation and demonstrating its' phases model, and section 5 presents the results of an evaluation of the system, ending with the conclusion.

\section{Related Work}

Gamification is definitely an interesting topic for education, using the principles of game, or game design technique to promote learning [11]. Gamification can increase student engagement it provides the learners with opportunities to apply and strategize previously acquired knowledge, and skills [3]. Also, there are two concepts that are often applied in education are: (1) Game-based learning - refers to the use of games to support learning, (2) Serious-games - specific games that have been developed with the intention of teaching [1].

The risk of gamification based learning becoming a game where people participate only to achieve the game components rather than to improve their skills or knowledge. They focus mainly on academic achievement, points, badges and leaderboards. Publications regarding higher education gamification research also often lack a theoretical underpinning that can help readers understand the researchers' motivation and the justifications for how their gamification approach is supported by any theory of change. This means that findings are difficult to generalize and don't really contribute to the larger body of gamification knowledge [12]. In many cases, admission to higher education can be given by analyzing, judging, testing the core concept. As a result, it will strengthen the level of education, its quality and automatically it will reduce unemployment to some extent [13].

Many published studies showed benefits from using gamification - new rapidly growing field - in education and training field. José and Diana (2016) addressed the actual use of gamification, the role of gender, age, and type of institution teachers are serving (public or private). The results show that no differences in use of gamification by age, gender or type of institution (public or private), and the teachers' attitude towards gamification are positive [14]. A study by Mehmet and Nihan (2016) applied 
gamification on science teaching software in control group. The study proof that gamification can motivate students to engage in the classroom, give teachers better tools to guide and reward students, and get students focus learning [15].

Another study by Luis and others (2016) analyzes the structure of the social network resulting from a gamified social undergraduate course as well as the influence that student's position has on learning achievement. The study focuses on the social gamification of e-learning to analyze the effects of gamification in the resulting structure of the network and it also examines how the position of each particular learner impacts in her learning performance [16].

Helena and Jorge (2015) Create a model for applying gamification in higher education to be applied in a course of Human Resource Management for Masters in Engineering, the model creates more student engagement and participation [3].

A study by Bastian and Carsten (2015) introduced a game concept for teaching in universities. The concept covers a level based storyline with rules and goals using physical artifacts of Mindstorms. By playing the conceptual game, a "free playing space" for students is established, e.g. different machine tools with different functionalities. The study proof that gamification has the potential to increase the learning and teaching productivity [17]. Gamification can motivate student engagement and participation. To summarize although the amount of literature on gamification in education, requires more studies of different gamification techniques in order to assess their efficiency.

\section{Research Methodology}

The study capture the relations of the students' motivations, data was gathered through a literature study on performed actions, statistics on the taken courses, points, and grades. The gathered data used to validate scales to measure the students' involvement and motivation served as input to the data set. Subjects divided into experimental groups receiving different treatments to analyze the effect of treatment on the dependent variables. The dependent variables are measured after exposing experimental treatment groups. The mean difference between groups is examined to see what the effect of manipulation is. The experimental group size 115 student. To assess the efficiency of the gamification manipulation of the study, ANOVA (Analysis of variance) test was used for data analysis [18].

\section{Proposed Framework}

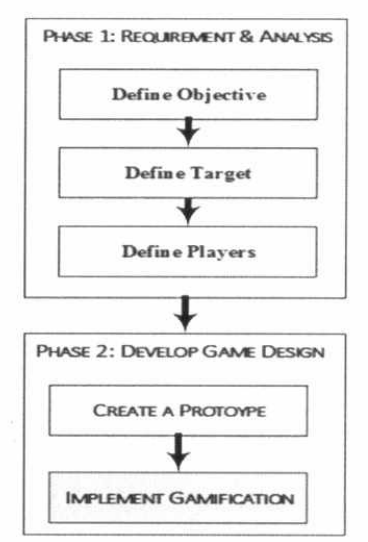

Figure 1: Proposed Gamification Framework. 
As it is illustrated in Figure 1, the proposed model consists of two phases, 1) Requirement and Analysis, 2) Game Design Development.

\section{A. Phase 1: Requirement and analysis}

The first step in this phase define the course objectives: grade students based on what they learned, and their engagement. The second step defines target: acquiring new information from the test case course materials; finding new information individually; peer groups; presenting found information to the group; solving quizzes. The third step defines players: in this case, students will be divided into two groups. The first team will be educated on the current traditional learning system, and the second team will be educated on the gamified learning system.

\section{B. Phase 2: Develop Game Design}

In this phase create a prototype for course, the students need to be graded. The game will be divided into stages. Each stage corresponds to a certain topic of the course, after each topic, there's a quiz. For every activity students, they will earn points, in case if the student earns amount number of points, the student will receive a badge and get high level.

Figure 2, shows the algorithms and flow chart for the gamification procedure. A student enrolled in a course, student study the material and take a quiz. If the student answers the quiz correct, he will receive points and get the second level of questions, else he will receive another quiz with an easy question then after progress he can be promoted to the second level of questions. The next step if the student gets a mounting number of points he will receive a badge belong to the current passed model. The amount number of points and badges gained, make student achieves a new level until becomes a leader board.

The second step in this phase implement gamification, the system shows engagement of the students through providing improvements done throughout the course in form of charts, points, badges, and leader boarding.

\begin{tabular}{|c|l|}
\hline \multicolumn{2}{|l|}{ First: Define the Problem } \\
\hline Problem: & $\begin{array}{l}\text { Identify how the elements of gamification affect user experience, and } \\
\text { increase their engagement with registered subjects. }\end{array}$ \\
\hline Input: & $\begin{array}{l}\text { Exams with dynamic question selection approach contain random questions, } \\
\text { with different levels (easy, medium, and hard) based on the gamification } \\
\text { tactics. }\end{array}$ \\
\hline Processing: & $\begin{array}{l}\text { The student enrolled in a course and take a quiz. If the student answers the } \\
\text { quiz correct, he will receive points and get the second level of questions, else } \\
\text { he can retake the exam with easy level. }\end{array}$ \\
\hline Output: & Students get points, and badges until becoming A leader board. \\
\hline
\end{tabular}




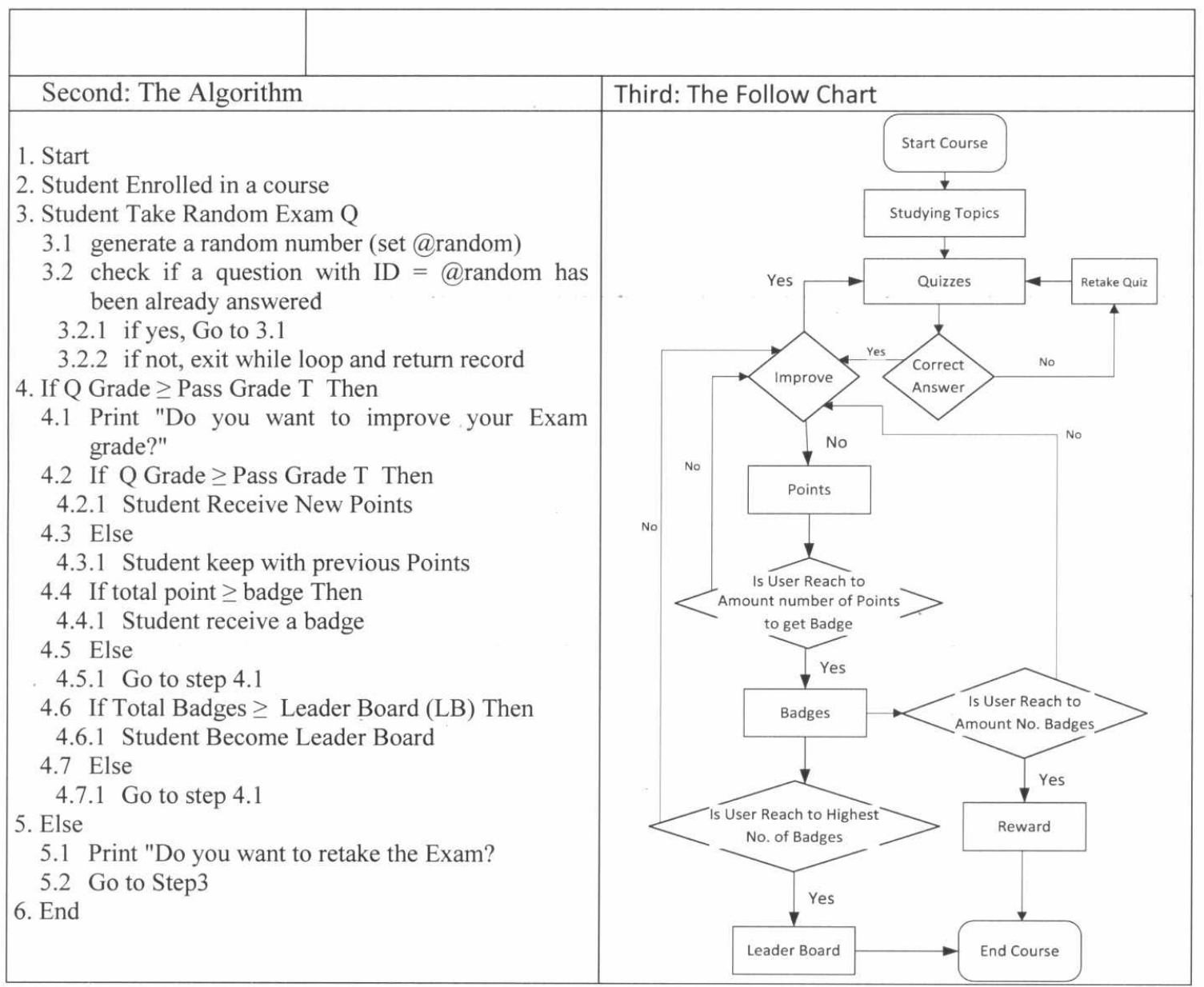

Figure 2: Algorithm and flowchart for gamified e-learning system.

\section{Experiments and Evaluation}

In this study, the gamification elements were applied to the LMS project. There were two experimental groups; non-gamified group (control group), and gamified group. To verify the results gathered, and ensure that the gamification tool determines the engagement, motivation, and participation among all students in the course, and encouraged students' active participation in the educational process, student behavior was tracked through receive reports from students' activities.

\section{A. Population and Sample}

To identify the student requirements on the system, a study has been conducted with the students. The number of respondents based on gender are shown in Table 1: 
Table 1: No. of Respondents based on Gender.

\begin{tabular}{|l|c|c|}
\hline Gender & No. of respondents & Percentage \\
\hline Female & 39 & $34 \%$ \\
\hline Male & 76 & $66 \%$ \\
\hline Total & 115 & $100 \%$ \\
\hline
\end{tabular}

The study result shows that $(72 \%$ student $)$ prefer to learn by following the structured content of the course and $28 \%$ choose random contents. All of the students prefer to conduct a quiz after finishing every module as shown in table 2 .

Table 2: Learning progress processing, time spent to learn, and test after each chapter.

\begin{tabular}{|l|l|c|}
\hline \multicolumn{2}{|c|}{} & Percentage \\
\hline \multirow{2}{*}{ Learning Progress Processing } & Structured Content & $72 \%$ \\
\cline { 2 - 3 } & Choose Randomly & $28 \%$ \\
\hline \multirow{3}{*}{ Time Spent to Learn } & 10 Minutes & $17 \%$ \\
\cline { 2 - 3 } & 10 to 30 Minutes & $61 \%$ \\
\cline { 2 - 3 } & $>30$ Minutes & $22 \%$ \\
\hline \multirow{2}{*}{ Test After Each Chapter } & Yes & $100 \%$ \\
\cline { 2 - 3 } & No & $0 \%$ \\
\hline
\end{tabular}

The constructed work of Gamified Learning Management System enables the administration to easy management of course materials. Gamified based learning allows the students to interact with teachers. It is also possible to maintain the documents and resources' which are needed by the students for their academic use. The system has the following functional units: (Student Management, Courses Management, Quizzes Management, Question Bank, Results Management, and Administration Dashboard). The next figures show snapshots from the gamified based learning system, figure 3 display system login screen, figure 4 student user interface display available courses and quizzes for the student. Regarding the visual representation, Microsoft PowerPoint-based slides have been used, where the storyline is written out. An example for this can be seen in figure 5. Student's achievement display exams status and achieved badges, figure 6 .

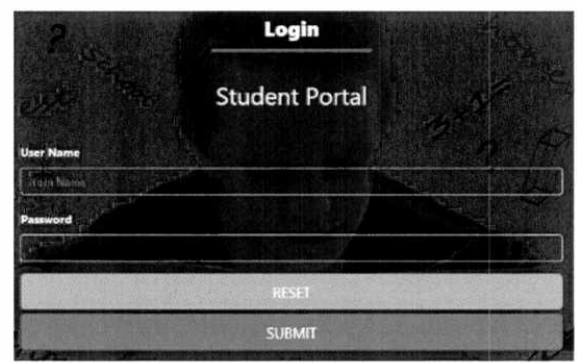

Figure 3: System Login Screen. 


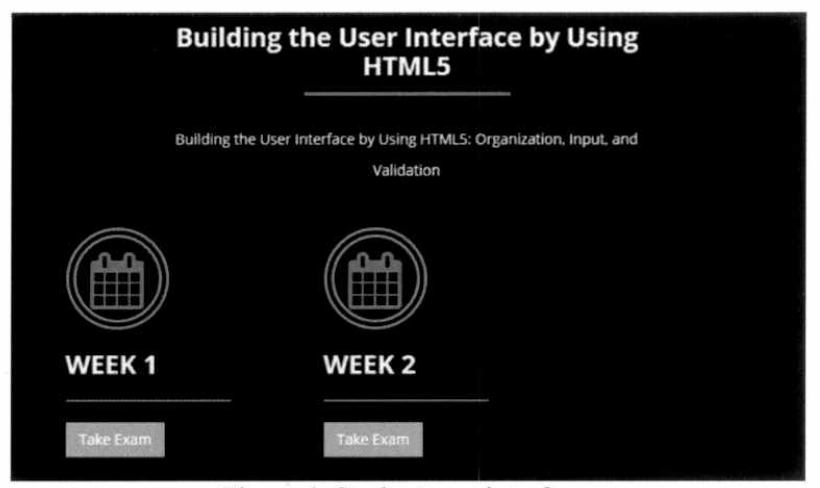

Figure 4: Student user interface.

Speak English Like American - Lesson 3 (10035iot:35

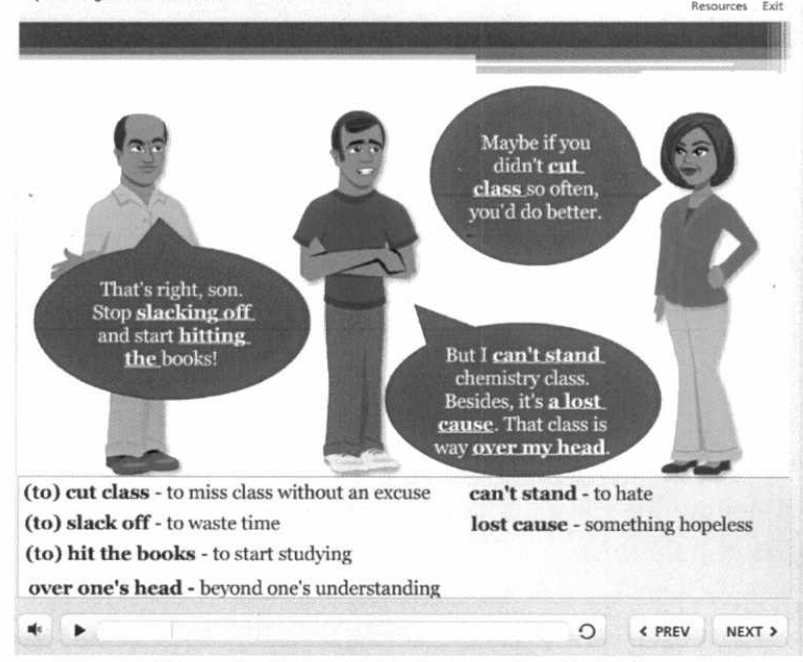

Figure 5: Example for the graphical interface.

(2) Score :240

\begin{tabular}{|c|c|c|c|c|c|c|c|c|}
\hline if & name & course & week & status & grade & prev grade & points & prev points \\
\hline 1 & Abelrahman & Bullding the User Interface by Using HTMLS & 1 & pass & $80 \%$ & $50 \%$ & 320 & 130 \\
\hline 4 & Khalid & Building the User Interface by Using HTML5 & 1 & pass & $80 \%$ & $75 \%$ & 320 & 230 \\
\hline 5 & Marwa & Building the User Interface by Using HTML5 & 1 & pass & $65 \%$ & $40 \%$ & 240 & 110 \\
\hline 6 & Moaz & Bullding the User Interface by Using HTML5 & 1 & pass & $75 \%$ & $75 \%$ & 300 & 240 \\
\hline 7 & Nour & Building the User Interface by Using HTMLS & 1 & pass & $80 \%$ & $75 \%$ & 320 & 230 \\
\hline 8 & Omnia & Building the User Interface by Using HTMLS & 1 & pass & $75 \%$ & $45 \%$ & 290 & 130 \\
\hline 9 & Sherif & Building the User Interface by Using HTMLS & 1 & pass & $80 \%$ & $75 \%$ & 320 & 230 \\
\hline 10 & Haroun & Building the User Interface by Using HTML 5 & 1 & pass & $80 \%$ & $75 \%$ & 320 & 240 \\
\hline
\end{tabular}

Figure 6: Student Achievements. 


\section{B. ANOVA Test}

To assess the efficiency of the gamification manipulation of the study - ANOVA (analysis of variance) is a way to test the hypothesis [19].

- Research Hypothesis $\left(\mathrm{H}_{\mathrm{a}}\right)$ : there is a significant difference between student behavior toward gamified based learning system and traditional learning.

$$
\mathbf{H}_{\mathrm{a}}: \mu_{1} \neq \mu_{2}
$$

Where $\mathrm{H}_{\mathrm{a}}=$ Research Hypothesis, $\mu_{1}=$ Means for Traditional Group, and $\mu_{2}=$ Means for Gamified Group.

- Null Hypothesis $\left(\mathrm{H}_{0}\right)$ : there is no a significant difference between student behavior toward gamified based learning system and traditional learning.

$$
\mathrm{H}_{0}: \mu_{1}=\mu_{2}
$$

Where $\mathrm{H}_{0}=$ Null Hypothesis, $\mu_{1}=$ Means for Traditional Group, and $\mu_{2}=$ Means for Gamified Group.

\section{Summary Statistics}

The minimum grade that student achieved was 50, the maximum grade was 96 with average 73.80 , and the standard deviation $\sigma$ (spread out sample numbers) equal 13.865 for control group 1 (see equation 1).

$$
\boldsymbol{\sigma}=\sqrt{\frac{\sum(\mathbf{x}-\overline{\mathbf{x}})^{2}}{\mathrm{~N}}}
$$

Where $\sigma=$ the standard deviation, $\mathrm{x}=$ each value in the population, $\overline{\mathrm{x}}=$ the mean of the value, and $\mathrm{N}=$ the number of values (the population).

To calculate the main $\overline{\mathrm{x}}$ :

$$
\overline{\mathbf{x}}=\frac{\sum \mathbf{x}}{\mathbf{N}}
$$

While the student achieved 85 as a minimum grade, the maximum grade was 100 , and the standard deviation $\sigma$ equal 4.831 for the gamified group. The results summarized in (table 3 ). Figure 7 show the standard deviations for the two groups, and Figure 8 show means grade for groups.

Table 3: Summary statistics

\begin{tabular}{|c|c|c|}
\hline Variable & Traditional Group 1 & Gamified Group 2 \\
\hline Observations & 50 & 65 \\
\hline$\%$ & 43.478 & 56.522 \\
\hline Minimum Grade & 50.00 & 85.00 \\
\hline Maximum Grade & 96.00 & 100.00 \\
\hline Mean & 73.80 & 94.30 \\
\hline Std. deviation $\sigma$ & 13.865 & 4.831 \\
\hline
\end{tabular}

92 


\section{STD. DEVIATION}
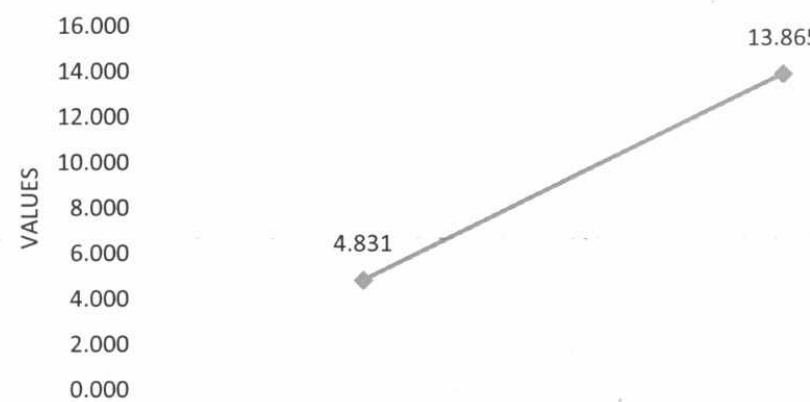

GAMIFIED LEARNING

TRADITIONAL LEARNING

Figure 7: Standard Deviation for Gamified Learning Group and Traditional Learning Group.

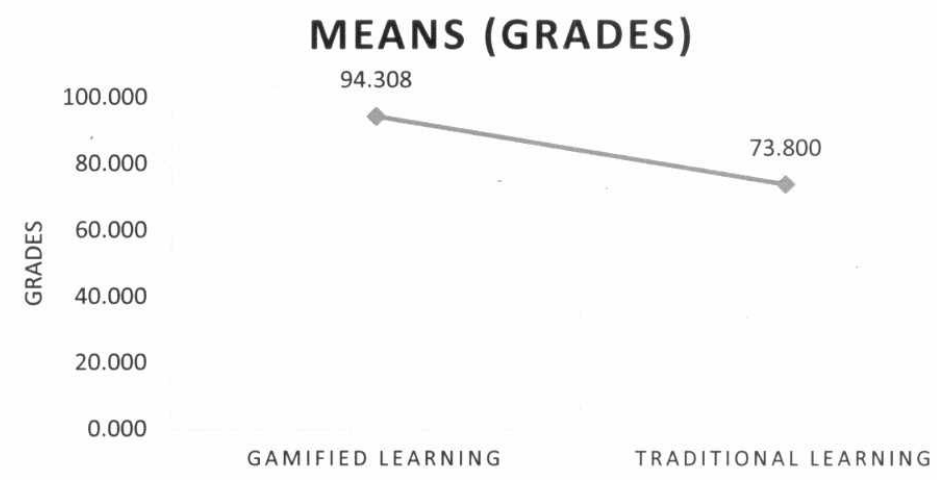

Figure 8: Means (Grades) - Traditional and Gamified learning Groups.

Table 4 categorized the student grades in gamified group 2 to four categories $(85,90,95,100)$ and display the frequencies of students grade in each category (Frequencies of an event $\boldsymbol{i}$ is the number $\boldsymbol{n}_{\boldsymbol{i}}$ of times the event occurred in an experiment or study).

Table 4: Gamified Group 2 Results:

\begin{tabular}{|c|c|c|c|}
\hline Variable & Categories & Frequencies & $\%$ \\
\hline \multirow{3}{*}{$\begin{array}{c}\text { Gamified } \\
\text { Group }\end{array}$} & 85 & 7 & 10.77 \\
\cline { 2 - 4 } & 90 & 14 & 21.54 \\
\cline { 2 - 4 } & 95 & 25 & 38.46 \\
\cline { 2 - 4 } & 100 & 19 & 29.23 \\
\hline
\end{tabular}

The results of the analysis of variance (see table 5) determine whether or not the explanatory variables bring significant information (null hypothesis $\mathrm{H}_{0}$ ) to the model. 
Table 5: Analysis of variance (Result):

\begin{tabular}{|c|c|c|c|c|c|}
\hline Source & DF (Degree of Freedom) & Sum of squares & Mean squares & F & $\operatorname{Pr}>$ F \\
\hline Model & 1 & 11885.545 & 11885.545 & 123.061 & $<0.0001$ \\
\hline Error & 113 & 10913.846 & 96.583 & & \\
\hline Corrected Total & 114 & 22799.391 & & & \\
\hline
\end{tabular}

Given the fact that the probability corresponding to the F value is lower than 0.0001 , that's main there's a lower than $0.01 \%$ risk in assuming that the null hypothesis is wrong. Therefore, there is a significant difference between student behavior toward gamified based learning system and traditional learning system.

The ANOVA test shows that the means aren't all equal, and p-value less than $\boldsymbol{\alpha}$. So the next step is to determine which means are different, by performing post-hoc analysis, see table 6 .

Table 6: Groups / Tukey (HSD) / Analysis of the differences between the categories with a confidence interval of $95 \%$

\begin{tabular}{|c|c|c|c|c|c|}
\hline \multicolumn{1}{|c|}{ Contrast } & Difference & $\begin{array}{c}\text { Standardized } \\
\text { difference }\end{array}$ & Critical value & Pr $>$ Diff & Significant \\
\hline $\begin{array}{l}\text { Gamified Learning vs } \\
\text { Traditional Learning }\end{array}$ & 20.508 & 11.093 & 1.981 & $<0.0001$ & Yes \\
\hline \begin{tabular}{l} 
Tukey's d critical value: \\
\hline
\end{tabular}
\end{tabular}

The previous table compares gamified learning group 2 vs traditional learning group 1 treatment, the next column display the difference between the sample means $\left(\overline{\mathbf{x}}_{\mathbf{i}}-\overline{\mathbf{x}}_{\mathbf{j}}\right)$ of group 2 and group 1 were $(94.308-73.800)$ as shown in table 3 and the difference equals 20.508 . Next is the standard error square-root term - equal 11.093, Next is a critical value of $\mathrm{q}=1.981$. The last column says there's a significant difference between the two treatments. Then the null hypothesis of equality rejected.

\section{MANOVA Test}

Wilks' lambda is a statistic test used in multivariate analysis of variance (MANOVA) to test whether there are differences between the means of identifying groups of subjects on a combination of dependent variables. Wilks' lambda performs, in the multivariate setting, with a combination of dependent variables, the same role as the F-test performs in a one-way analysis of variance [20].

The parity test MANOVA has been applied in order to understand the Effectiveness of Gamified based E-Learning System on group 2. It is inferred that there is a significant difference exist between the student results since the null hypothesis is rejected. The obtained significant value of first and improvement exam 0.004. This value is less than the fixed significant value (i.e., $\mathrm{p}<0.05$ ). It informs that the Effectiveness of Gamified based E-Learning System was good, see table 7.

Table 7: Wilks' test (Rao's approximation) for Gamified Group 2

\begin{tabular}{|l|c|c|}
\hline & Retake Exam & Improve Exam \\
\hline Lambda & 0.196 & 0.409 \\
\hline F (Observed values) & 27.212 & 25.565 \\
\hline DF1 & 8 & 3 \\
\hline DF2 & 53 & 53 \\
\hline F (Observed values) & 2.119 & 2.779 \\
\hline p-value & $<0.0001$ & $<0.0001$ \\
\hline
\end{tabular}


From table 7, Lambda is a probability distribution used in multivariate hypothesis testing, especially with multivariate analysis of variance (MANOVA). The $F$ indicates using an $F$ test, The 8 and 53 are the two degrees of freedom values $(\boldsymbol{d} f)$ for the between groups "effect" and the within-groups "error". As the computed p-value is lower than the significance level alpha $=0.05$, one should reject the null hypothesis $\mathrm{H}_{0}$, and accept the alternative hypothesis $\mathrm{H}_{\mathrm{a}}$. Figure 9 compare student results (quiz results, retake, and improvement grades)

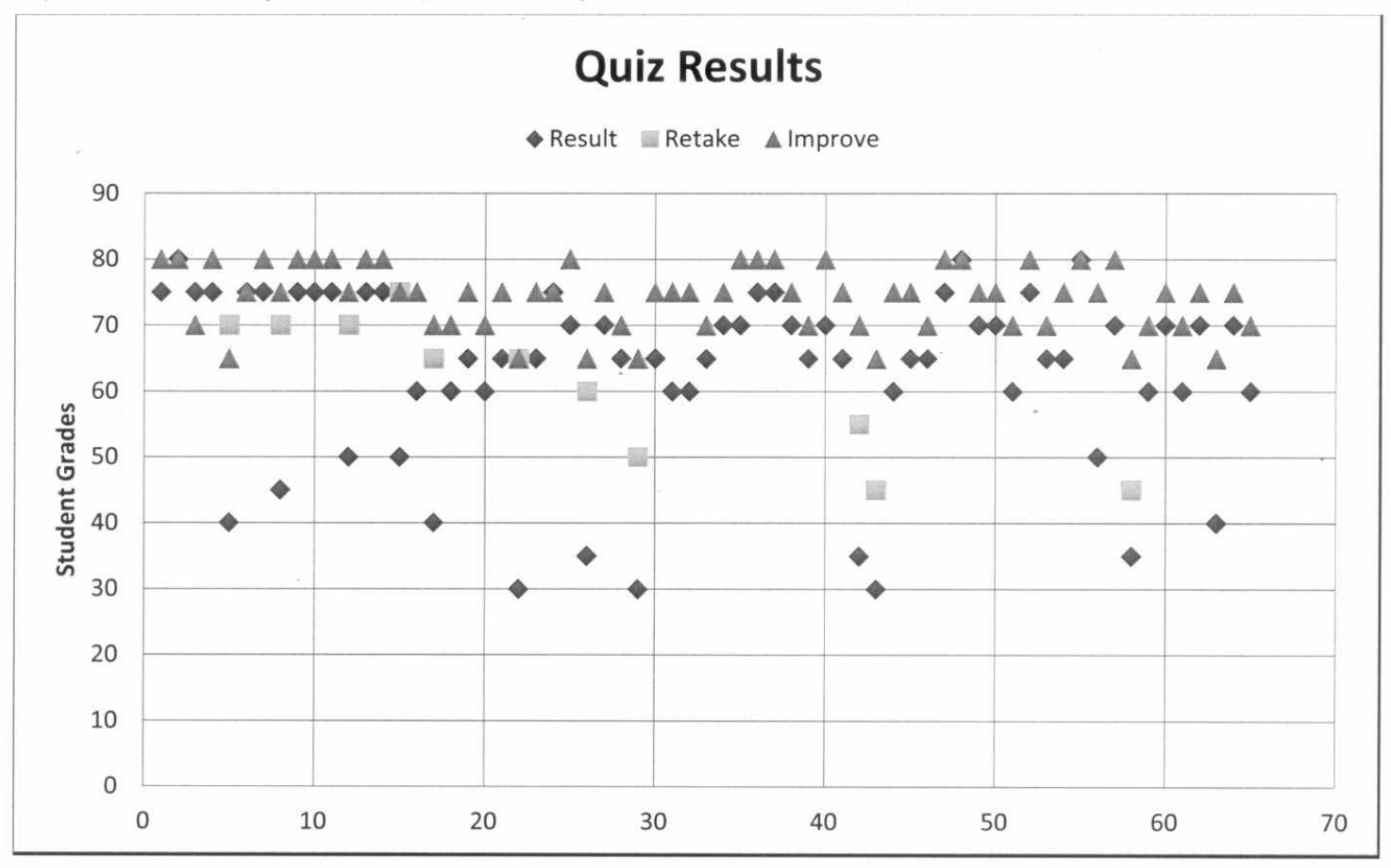

Figure 9: Quiz Results, Retake, and Improvement Grades.

\section{Conclusion}

The proposed model applied gamification to Learning Management System to affect student activity, engagement, involvement, and motivation, and adopt the new behavior. Gamification was defined as the use of game design elements in non-game contexts, in order to increase engagement and motivate certain behavior. Examples of this elements are the use of badges, avatars, leaderboards, elements of time pressure and many other elements found in games. In this research, gamification applied to elearning system. There were two experimental groups: a control group that had no gamification, and a gamified group. Based on the analysis of results, students enjoyed receiving points on gamified elearning system and indicated to know which activities would earn those points. The gamified group had performed more activities than another non-gamified group. This means that the gamification applied to the LMS had a significant effect on students, and increased the engagement. So, the gamification has positive effects on students. 


\section{References}

1. S. Deterding, D. Dixon, R. Khaled, and L. Nacke (2011), "From game design elements to gamefulness: Defining Gamification", Proceedings of the 15th International Academic MindTrek Conference, pg. 9-15.

2. K. Werbach, and D. Hunter (2012), "For The Win: How Game Thinking Can Revolutionize Your Business", Published by Wharton Digital Press, The Wharton School, University of Pennsylvania, 3620 Locust Walk - 2000 Steinberg Hall-Dietrich Hall - Philadelphia, PA 19104

3. H. Martins, and J. Freire (2015), "Games People Play - Creating A Framework for The Gamification of A Master's Course in A Portuguese University", Proceedings of ICERI2015 Conference 16th-18th November 2015, Seville, Spain, ISBN: 978-84-608-2657-6, pg. 2821-2827

4. G. Surendeleg, V. Murwa, H. Yun-Kyung, and Y. Kim (2014), " The Role of Gamification in Education- A Literature Review", Contemporary Engineering Sciences, HIKARI Ltd, www.m-hikari.com, Volume 7, 2014, no. 29, pg. 1609 - 1616, Online Available: http://dx.doi.org/10.12988/ces.2014.411217

5. J. Hamari, J. Koivisto, and H. Sarsa (2014), "Does Gamification Work? - A Literature Review of Empirical Studies on Gamification", 47th Hawaii International Conference on System Science, 978-1-47992504-9/14, pg. 3025-3034

6. True Life Game (2016), " True Life Game - Gamification of Knowledge and Life", Online Available: http://www.truelifegame.com/, retrieved date $17^{\text {th }}$ Nov. 2016.

7. A.S.U (2016), "ASU Online Pilots Games for Environmental Science", Online Available: http://asuonline.asu.edu/about-us/newsroom/asu-online-pilots-games-environmental-science, retrieved date $17^{\text {th }}$ Nov. 2016

8. D. Dicheva, C. Dichev, G. Agre, and G. Angelova (2014), "Gamification in Education: A Systematic Mapping Study", T Journal of Educational Technology \& Society, ISSN 1436-4522. 18 (3), pg. 75-88.

9. A. Marczewski (2015), "48 Gamification elements, mechanics and ideas - Gamified UK Gamification Consultancy", Online Available: https://www.gamified.uk/2015/02/04/47-gamification-elementsmechanics-and-ideas/, retrieved date $5^{\text {th }}$ Nov. 2016.

10. World Government Summit (2016), "GAMIFICATION AND THE FUTURE OF EDUCATION", Oxford Analytica Ltd, United Kingdom. Online Available: http://www.oxan.com, retrieved date $5^{\text {th }}$ Nov. 2016.

11. S. Borges, V. Durelli, H Reis, and S. Isotani (2014). "A systematic mapping on gamification applied to education". Proceedings of the 29th Annual ACM Symposium on Applied Computing (SAC '14). pg. 216222.

12. M. Mejias, K. Jean-Pierre, Q. Knox, E. Ricks, L. Burge, and N. Washington (2016), "Meaningful Gamification of a Computer Science Department: Considerations and Challenges", session use of robots, gamification, and other technologies in education, Int'l Conf. Frontiers in Education: CS and CE - FECS'15, pg. $10-15$

13. M. Satoskar (2016), "Cognitive Prior-Knowledge Testing Method for Core Development of Higher Education of Computing in Academia", session use of robots, gamification, and other technologies in education, Int'l Conf. Frontiers in Education: CS and CE - FECS'15, pg. 290-294

14. J. Martí-Parreñoa, D. Seguí-Masa, and E. Seguí-Masb (2016), "Teachers' Attitude towards and Actual Use of Gamification", Procedia - Social and Behavioral Sciences 228, 1877-0428, pg. $682-688$

15. M. Şahin, and N. Arslan (2016) "Gamification and Effects on Students' Science Lesson Achievement", International Journal on New Trends in Education and Their Implications, Volume: 7 Issue: 1 Article: 04 ISSN 1309-6249, pg. 41-47.

16. L. de-Marcos, E. García-Lopez, A. García-Cabot, and others (2016), "Social network analysis of a gamified e-learning course: Small-world phenomenon and network metrics as predictors of academic performance", Computers in Human Behavior 60, pg. 312-321 
17. B. Müllera, C. Reise, and G. Seligera (2015) "Gamification in factory management education - a case study with Lego Mindstorms", 12th Global Conference on Sustainable Manufacturing, Procedia CIRP 26, pg. 121 $-126$.

18. XLSTAT (2017), "Statistical software \& data analysis add-on for Excel | XLSTAT", Online Available: https://www.xlstat.com/, retrieved date $5^{\text {th }}$ Nov. 2016.

19. H. Seltman (2015) "Experimental Design and Analysis", Online Available: http://www.stat.cmu.edu/ hseltman/309/Book/Book.pdf, retrieved date $5^{\text {th }}$ Feb. 2017.

20. A. French, M. Macedo, J. Poulsen, T. Waterson, and A. Yu (2008), "Multivariate Analysis of Variance (MANOVA)", Online Available: http://online.sfsu.edu/efc/classes/biol710/manova/MANOVAnewest.pdf, retrieved date $5^{\text {th }}$ Feb. 2017. 